\begin{tabular}{ccc}
\hline International Journal of Engineering \& Technology, $7(1.1)(2018) 116-120$ \\
SPC \\
Website $:$ ww.sciencepubco.com/index.php/IJET \\
Research paper
\end{tabular}

\title{
Design of a multi criteria decision model-fuzzy analytical hierarchy approach
}

\author{
P. Sona ${ }^{*}$, T. Johnson ${ }^{2}$, C. Vijayalakshmi ${ }^{3}$ \\ ${ }^{1}$ Department of Mathematics, Dr.MGR Educational and Research Institute University, Chennai. \\ ${ }^{2}$ Department of Mathematics, Dr.MGR Educational and Research Institute University, Chennai. \\ ${ }^{3}$ SAS, Mathematics Division, VIT University, Chennai. \\ *Corresponding author E-mail:sonamaheshkanna@gmail.com
}

\begin{abstract}
In Supply Chain Management(SCM),vendor selection has become a very important activity. By selecting the appropriate vendor, companies can avoid barriers and do for efficient production. The aim of this paper is to identify the important criteria that may develop strategies of the organizations. It deals with the analysis of vendor selection problem using Fuzzy Analytical Hierarchy Process (FAHP).The comparison has made between the parameters criteria and alternatives by designing a model of uncertainty. The proposed method has applied in an automobile industry to choose their vendors in a best way.
\end{abstract}

Keywords: Fuzzy analytical hierarchy process, multi criteria decision making, SCM, linguistic terms, defuzzification, normalization, comparison matrix, consistency index.

\section{Introduction}

\subsection{Multi criteria decision making(MCDM)}

Decision Making plays a vital role in the real-time applications and come under a branch of a general class of Operations Research, which deals with decision problems with respect to many decision criteria. Consequences are implied by decisionmaking problem that the decision maker estimates it more reasonable than others, on the other side no choice would be possible [Maria Grazia D'urso et al.,2015].For modeling uncertain industrial, natural and human systems, fuzzy sets and fuzzy logic are powerful mathematical tools and they are facilitator in decision-making with about approximate reasoning and linguistic terms[Madjid Tavana et al., 2013]. So Fuzzy Analytical Hierarchy algorithm can be applied to have estimates which are an appropriate mathematical tool.

\subsection{Vendors in a manufacturing industry}

Anyone who provides goods or services to a company or people is known as a vendor. They manufacture inventories items and sell them to customers. To lead successful company, vendor relationship plays a vital role of successful procurement. Vendor selection is the first step of the activities in the production management task and it is a Multi Criteria Decision Making problem. Selecting the most appropriate vendor is considered as an important decision that may impact the performance of production management. The vendor selection process is also used to identify potential risks in the supply chain management. To service in the competitive global economy, it is important not only to develop existing vendors but also to discover new one.

\section{Literature survey}

The two main aspects of the supplier selection process are (a) the selection of criteria for taking decisions, and (b) choosing a method for ranking the available suppliers [AlessioIshizaka 2014]. OzcanKilincci et al., (2011) have made an analysis of Fuzzy AHP to select the supplier in Washing Machine Company. They have taken three main attributes and fourteen sub-attributes and fuzzy AHP based approach is presented to select the best supplier firm providing the most customer satisfaction for that company. S.Gold et al.,(2015) has analyzed sustainable global supplier selection extended towards sustainability risks from $(1+n)$ th tier supplier using Fuzzy AHP based approach. Mustafa BatuhanAyhan (2013) approached supplier selection problem using fuzzy AHP in a gear motor company.

Ruth Mwikali et al. (2012) has analyzed about the factors affecting the selection of optimal suppliers in procurement management. Ana Cristina et al. (2014) has discussed about the quality management and supply chain management. Harish kumarsharma (2012) has approached vendor selection by fuzzy logic Multi Criteria Decision Making. Rajesh Singh et al. (2011) have used fuzzy AHP for supplier selection. According to the current business scenario they have selected the main and sub criteria. They analyzed and discussed each factor affecting the supply of the product. AndrasSzuts et al. (2015) has developed a fuzzy analysis hierarchy process for changes the energetically optional solution at the early design phase of a Building. C. Kavithaet al. (2013) has used improved TOPSIS for supplier evaluation. MadjidTavana et al. (2013) has applied fuzzy inference system to select player and to form team in multi-player sports. Maria GraziaD'urso et al. (2015) has made an analysis about Multi Criteria Decision Making and applied this for human resources. They have taken four criteria and twenty one sub criteria for evaluating criteria to adopt for human resources in the 
field of science and technology. Rajnish Kumar (2013) has made an analysis about supplier selection criteria. Sachin K. Patilet al., (2014) has made a framework in fuzzy AHP-TOPSIS for ranking the solution in supply chain. They used fuzzy AHP to get weights of the barriers of knowledge management adoption in supply chain, while fuzzy TOPSIS is used to rank solutions. Yu-Chang Tang et al., (2011) has discussed about the application of the fuzzy analysis hierarchy process to the lead free equipment selection decision. C. Kavitha et al.,(2013)has implemented Fuzzy Multi Objective Optimization Model for Production Planning. Chang D.Y (1996) has analyzed about the application of the extent analysis method on fuzzy AHP. Alessio Ishizaka (2014) has compared fuzzy logic, AHP, FAHP and Hybrid fuzzy AHP for new supplier.

\section{Criteria used for vendor selection}

So many factors affect the vendor selection process. But we consider some important criteria according to expert's opinion. They are

- Quality (C1)

- $\quad$ Price $(\mathrm{C} 2)$

- Delivery (C3)

- $\quad$ Service (C4)

- Performance History (C5)

\subsection{Quality}

Quality is one of the main criteria for vendor evaluation and vendor selection. Quality refers to the ability of the products according to the customer expectations. It also includes product reliability, quality systems. More over the vendor should understand the quality policies of the buyer. If a buyer gives more important to the raw material, then it will reflect in the end product. Quality has become an increasingly important issue in industries and so it is essential to develop it to obtain competitive advantages [Ana Cristina Fernandas2014]. Quality consists more factors such as life of the product, ease of use, ease of repair etc. [John J Coyleet al.,2003].

\subsection{Price}

In today's competitive environment pricing is one of the deciding criteria. This criterion is evaluated by price/cost scale according to the buyer's specifications. A product can be priced according to many factors such as freight cost, material cost, maintenance cost etc. Whenever the customer buys raw material from the vendor, they have to check the price compulsorily because this price will reflect in the final product cost of the end product. So this criterion plays an important role in the vendor selection process. To sell a product in nominal cost, one has to procure raw material within a suitable range of price without affecting the quality of the product. The customer always requires minimum price of product to increase the profit [Ruth Mwikaliet al.,2012]. Profit maximization cannot be achieved without the cost minimization[Rajesh singh et al.,2011]. Purchasing managers utilize four basic procedures to determine potential vendor's prices such as commodity markets, price lists, price quotations, and negotiations [John J Coyleet al., 2003].

\subsection{Delivery}

Delivery is one of the most important criteria for a vendor to qualify. Vendors should have ability to meet delivery promise. Suppose a vendor gives the good quality raw material in late delivery, then it is not beneficial to the buyer. So the vendor should have proper monitoring system for delivery. The ability of the vendor to follow the predefined delivery schedule is always the prime criteria for selection in this fast moving world[Rajesh singh et al.,2011].

\subsection{Service}

Service is also one of the important criteria. A buyer has to analize service pattern of the vendor. Apart from all other factors, if there are any defects in the quality or quantity or any delay in delivery then the vendor should handle this type of problems in a proper way. So this service factor includes complaints handling attitude, ability of problem solving aids etc. A good service may increase the customer base. Enactment of the vendor by providing service to the manufacturer is the prime criteria to decide its aptness for a particular product[Rajesh singh et al.,2011].Vendors need experienced technical ability, to offer good service [Ruth Mwikaliet al.,2012].

\subsection{Performance history}

The most consistent vendor can even slip up some times, so the buyer has to manner a regular performance reviews. Companies send a skillful team to the vendor site generally and evaluate different criteria and factors. Under this performance history criteria, buyer has to check its past manufacture schedule, reaction to market and its facility to make commercial relations[Ruth Mwikali et al.,2012].For vendors credit can be given according to this criterion for market reputation and delivery performance. In taking correct decision for the selection of vendors, the performance and past history of them help [Ruth Mwikaliet al.,2012].

\section{Mathematical model formulation}

\section{Fuzzy analytic hierarchy process(FAHP)}

AHP is a multi criteria decision-making method. Using AHP, we can evaluate and then select the alternative according to the set of required criteria. Many researches have applied AHP method in many decision-making problems such as vendor selection, personal selection etc.

AHP cannot perform well in the uncertainty level. In classical AHP method the preparation of pairwise comparison is a highly labor intensive process and its effectiveness is questionable [AndrasSzuts et al.,2015]. So Fuzzy AHP combines AHP with Fuzzy logic to solve Fuzzy hierarchical problems. Fuzzy AHP method captures uncertain imprecise judgments of experts using linguistic variables. In current days, Fuzzy AHP is used to solve many MCDM problems.

To handle the fuzziness of the data involved in deciding the preferences of different decision variables, Fuzzy-AHP performs as an efficient tool[Rajesh singh et al.,2011]. Using classical AHP, it is very difficult to map human judgments. According to FuzzyAHP, pair wise comparisons have done using fuzzy linguistic preference scale[Rajesh singh et al.,2011].Many researchers have used different Models in Fuzzy AHP. In our paper we follow the model[Mustafa Batuhan AYHAN2013] from Buckley's method. The steps are given below.

\section{Step 1: Pairwise comparison between criteria}

Compare the criteria and alternatives using linguistic terms. Linguistic terms and the corresponding triangular fuzzy numbers are given in the following table.

Table 1: Numerical Representation of Fuzzy

\begin{tabular}{|l|l|}
\hline Linguistic Variable & Fuzzy Triangular Scale \\
\hline Equally Important & $(1,1,1)$ \\
\hline Moderately Important & $(2,3,4)$ \\
\hline Strongly Important & $(4,5,6)$ \\
\hline Very Strongly Important & $(6,7,8)$ \\
\hline Extremely Important & $(9,9,9)$ \\
\hline
\end{tabular}

According to the above table, for example if we say that first criteria $(\mathrm{C} 1)$ is very strongly. Important than the second Criteria (C2), then it will be represented by the fuzzy triangular number as 
$(6,7,8)$. On the other hand, the pair wise comparison of $\mathrm{C} 2$ to $\mathrm{C} 1$ takes the fuzzy triangular number as $(1 / 8,1 / 7,1 / 6)$.

In equation (i) the pair wise comparison matrix is given, where $\widetilde{a_{l j}}$ denotes the preference(relative importance) of $i^{\text {th }}$ criterion over $j^{\text {th }}$ criterion, via fuzzy triangular numbers. The triangular number demonstration is represented by tilde ( ).For example, $\overline{a_{32}}$ represents the preference of $3^{\text {rd }}$ criterion over $2^{\text {nd }}$ criterion.

$$
\tilde{A}=\left[\begin{array}{ccccc}
\widetilde{a_{11}} & \widetilde{a_{12}} & . . & . . & \widetilde{a_{1 n}} \\
\widetilde{a_{21}} & \widetilde{a_{22}} & . . & . . & \widetilde{a_{2 n}} \\
. . & . . & . . & . . & . . \\
. . & . . & . & . . & . . \\
\widetilde{a_{n 1}} & \widetilde{a_{n 2}} & . & . . & \widetilde{a_{n n}}
\end{array}\right]
$$

Step 2: Geometric mean of fuzzy comparison values of each criterion

The geometric mean of fuzzy comparison values of each criterion is calculated as shown in equation (ii).Here $\widetilde{g}_{l}$ represents triangular number.

$\widetilde{g_{l}}=\left(\prod_{j=1}^{n} a_{i j}\right)^{1 / n}, i=1,2, \ldots \ldots n$

\section{Step 3:Vector summation}

For each $\widetilde{g}_{l}$, find the vector summation.

Step 4:Increasing order

Find the reverse $((-1)$ power) of summation vector. Replace the fuzzy triangular number to make it an increasing order.

Step 5: Fuzzy weights of each criterion

Multiply each $\widetilde{g_{l}}$ with this reverse vector to find the fuzzy weight of criterion $\widetilde{w_{l}}$.

Weight of each criterion $=\widetilde{g_{l}} *\left(\widetilde{g_{1}} \oplus \widetilde{g_{2}} \oplus \ldots \oplus \widetilde{g_{n}}\right)^{-1}$

(ie) $\widetilde{w_{l}}=\left(l w_{i}, m w_{i}, n w_{i}\right)$

\section{Step 6:Defuzzification of triangular fuzzy number.}

The triangular fuzzy numbers need to defuzzify by centre of area method

$$
M_{i}=\frac{l w_{i},+m w_{i}+n w_{i}}{3}
$$

\section{Step 7: Normalization}

It needs to normalize the non-fuzzy number $M_{i}$ using equation (v)

$$
N_{i}=\frac{M_{i}}{\sum_{i=1}^{n} M_{i}}
$$

To find the normalized weights of both criteria and the alternatives, the above 7 steps are performed. The scores for each alternative are calculated by multiplying each alternative weight with related criteria. Then the alternative with the highest score is considered as the best vendor. An automobile company is considered to apply the above methodology as a case study.

\section{Results and discussions}

The proposed methodology is going to apply to one of the well named company in Chennai. They demand high quality products at optimum price value, with on time delivery and they expect quality certification for the vendors compulsory. They also check the vendors company by sending expert teams about the performance history of the vendor with the previous customers.

\section{Weights of Criteria}

According to the experts opinion the pair wise comparison matrix of the criteria is given below.
Table 2: Pair Wise Comparisons of Criteria

\begin{tabular}{|l|l|l|l|l|l|}
\hline Criteria & \multicolumn{1}{|c|}{ Quality } & \multicolumn{1}{|c|}{ Price } & Delivery & Service & $\begin{array}{l}\text { Performance } \\
\text { History }\end{array}$ \\
\hline Quality & $(1,1,1)$ & $(4,5,6)$ & $(6,7,8)$ & $(4,5,6)$ & $(1,1,1)$ \\
\hline Price & $(1 / 6,1 / 5,1 / 4)$ & $(1,1,1)$ & $\begin{array}{l}(1 / 4, \\
1 / 3,1 / 2)\end{array}$ & $(2,3,4)$ & $(1 / 6,1 / 5,1 / 4)$ \\
\hline Delivery & $(1 / 8,1 / 7,1 / 6)$ & $(2,3,4)$ & $(1,1,1)$ & $(1,1,1)$ & $(1 / 8,1 / 7,1 / 6)$ \\
\hline Service & $(1 / 6,1 / 5,1 / 4)$ & $(1 / 4,1 / 3,1 / 2)$ & $(1,1,1)$ & $(1,1)$, & $(1 / 6,1 / 5,1 / 4)$ \\
\hline $\begin{array}{l}\text { Performance } \\
\text { History }\end{array}$ & $(1,1,1)$ & $(4,5,6)$ & $(6,7,8)$ & $(4,5,6)$ & $(1,1,1)$ \\
\hline
\end{tabular}

Only if the consistency index (CI) $\leq 0.15$, the consistency of the matrix is consider as acceptable. The above comparison matrix table has $\mathrm{CI}=0.1284$. So consistency of our comparison matrix is acceptable.

At the second step, the geometric mean of fuzzy comparison values of each criterion is calculated by equation (ii). For example $\widetilde{g}_{1}$ geometricmean of fuzzy comparison values of Quality criterion is calculated as equation (vi).

$\widetilde{g_{1}}=\left(\prod_{j=1}^{n} a_{1 j}\right)^{1 / n}=\left[(1 * 4 * 6 * 4 * 1)^{\frac{1}{5}} ;(1 * 5 * 7 * 5 * 1)^{\frac{1}{5}} ;(1 * 6 * 8 * 6 * 1)^{\frac{1}{5}} ;\right]$

$=[2.491 ; 2.809 ; 3.104]$

Similarly the geometric mean of fuzzy comparison values of all criteria is given in the table 3 .

Table 3: Geometric Mean of Fuzzy Comparison Values of All Criteria

\begin{tabular}{|l|l|l|l|}
\hline Criteria & \multicolumn{3}{|c|}{$\widetilde{\boldsymbol{g}_{\boldsymbol{l}}}$} \\
\hline Quality & 2.491 & 2.809 & 3.104 \\
\hline Price & 0.425 & 0.525 & 0.660 \\
\hline Delivery & 0.5 & 0.572 & 0.644 \\
\hline Service & 0.370 & 0.422 & 0.5 \\
\hline Performance History & 2.491 & 2.809 & 3.104 \\
\hline Total & 6.278 & 7.138 & 8.012 \\
\hline Power of -1 & 0.16 & 0.14 & 0.12 \\
\hline Increasing order & 0.12 & 0.14 & 0.16 \\
\hline
\end{tabular}

In the next step, the fuzzy weight of Quality criterion $\widetilde{w_{1}}$ isgiven the equation (vii)

$$
\widetilde{w_{1}}=[(2.491 * 0.12) ;(2.809 * 0.14) ;(3.104 * 0.16)]
$$

$$
\begin{aligned}
& =[0.299 ; 0.393 ; 0.497]----\cdot--\cdot-----(\text { vii }) \\
& M_{1}=\frac{0.299+0.393+0.497}{3}=0.396
\end{aligned}
$$

Similarly the fuzzy weight of each criterion $\left(\widetilde{w_{l}}\right)$, non-fuzzy weight of each criterion $\left(M_{i}\right)$, normalized weights of each criterion $\left(N_{i}\right)$ is calculated and given in the table 4 .

Table 4: Fuzzy Weight $\left(\widetilde{w_{l}}\right)$, Non-fuzzy Weight $\left(M_{i}\right)$, Normalized Weights $\left(N_{i}\right)$ of Each Criterion

\begin{tabular}{|l|l|l|l|l|c|}
\hline Criteria & \multicolumn{3}{|c|}{$\widetilde{\boldsymbol{w}_{\boldsymbol{l}}}$} & $M_{i}$ & $\boldsymbol{N}_{\boldsymbol{i}}$ \\
\hline Quality & 0.299 & 0.393 & 0.497 & 0.396 & $\frac{0.396}{1.001}=0.396$ \\
\hline Price & 0.051 & 0.074 & 0.106 & 0.077 & $\frac{0.077}{1.001}=0.077$ \\
\hline Delivery & 0.06 & 0.08 & 0.103 & 0.081 & $\frac{0.081}{1.001}=0.081$ \\
\hline Service & 0.044 & 0.059 & 0.08 & 0.061 & $\frac{0.061}{1.001}=0.061$ \\
\hline Performance History & 0.299 & 0.393 & 0.467 & 0.386 & $\frac{0.386}{1.001}=0.386$ \\
\hline Total & & & 1.001 & \\
\hline
\end{tabular}

In the above table for example $N_{1}$ is calculated by $N_{1}=\frac{M_{1}}{\sum_{i=1}^{n} M_{i}}=$ $\frac{0.396}{1.001}=0.396$

\section{Weights of alternatives with respect to criteria}

The above methodology is applied to alternatives also. Before that the alternatives should be pair wise compared with respect to each criterion. Let $V_{1}, V_{2}, V_{3}$ be three vendors of the company.

Table 5: Pair Wise Comparisons of Alternatives with Respect to "Quality" Criterion

\begin{tabular}{|c|l|l|l|}
\hline Alternatives & \multicolumn{1}{|c|}{$V_{1}$} & \multicolumn{1}{|c|}{$V_{2}$} & \multicolumn{1}{|c|}{$V_{3}$} \\
\hline$V_{1}$ & $(1,1,1)$ & $(2,3,4)$ & $(4,5,6)$ \\
\hline$V_{2}$ & $(1 / 4,1 / 3,1 / 2)$ & $(1,1,1)$ & $(1 / 4,1 / 3,1 / 2)$ \\
\hline$V_{3}$ & $(1 / 6,1 / 5,1 / 4)$ & $(2,3,4)$ & $(1,1,1)$ \\
\hline
\end{tabular}

The above comparison matrix table has $\mathrm{CI}=0.1472$. So consistency of our comparison matrix is acceptable. Similarly the 
geometric mean of fuzzy comparison values of alternatives with respective to quality criterion is given in the table 6 .

Table 6: Geometric Mean $\left(\widetilde{\boldsymbol{g}_{\boldsymbol{\imath}}}\right)$ of Fuzzy Comparison Values of alternatives with Respective to Quality Criterion

\begin{tabular}{|l|l|l|l|}
\hline \multicolumn{1}{|c|}{ Alternatives } & \multicolumn{3}{|c|}{$\widetilde{\boldsymbol{g}_{\boldsymbol{\imath}}}$} \\
\hline \multicolumn{1}{|c|}{$V_{1}$} & 2.000 & 2.466 & 2.884 \\
\hline$V_{2} V_{3}$ & 0.397 & 0.481 & 0.630 \\
\hline Total & 0.693 & 0.843 & 1.000 \\
\hline Power of -1 & 3.090 & 3.790 & 4.514 \\
\hline Increasing order & 0.324 & 0.264 & 0.222 \\
\hline
\end{tabular}

Similarly the fuzzy weight of each alternatives $\left(\widetilde{w_{l}}\right)$, non-fuzzy weight of each alternatives $\left(M_{i}\right)$, normalized weights of each alternatives $\left(N_{i}\right)$ with respective to quality criterion is calculated and given in the table 7 .

Table 7: Fuzzy weight $\left(\widetilde{w_{l}}\right)$, Non-fuzzy Weight $\left(M_{i}\right)$, Normalized Weights $\left(N_{i}\right)$ of Each Alternative with Respect to Quality Criterion

\begin{tabular}{|c|c|c|c|c|c|}
\hline Alternatives & \multicolumn{3}{|c|}{$\widetilde{\boldsymbol{W}}_{\boldsymbol{l}}$} & $M_{\boldsymbol{i}}$ & $\boldsymbol{N}_{\boldsymbol{i}}$ \\
\hline$V_{1}$ & 0.443 & 0.651 & 0.933 & 0.676 & 0.645 \\
\hline$V_{2}$ & 0.088 & 0.127 & 0.204 & 0.139 & 0.133 \\
\hline$V_{3}$ & 0.154 & 0.222 & 0.324 & 0.233 & 0.222 \\
\hline Total
\end{tabular}

Now consider the pairwise comparison of alternatives according to price criterion.

Table 8: Pair Wise Comparisons of Alternatives with Respect to "Price" Criterion

\begin{tabular}{|c|l|l|l|}
\hline Alternatives & \multicolumn{1}{|c|}{$V_{1}$} & \multicolumn{1}{|c|}{$V_{2}$} & \multicolumn{1}{c|}{$V_{3}$} \\
\hline$V_{1}$ & $(1,1,1)$ & $(6,7,8)$ & $(2,3,4)$, \\
\hline$V_{2}$ & $(1 / 8,1 / 7,1 / 6)$ & $(1,1,1)$ & $(1 / 4,1 / 3,1 / 2)$ \\
\hline$V_{3}$ & $(1 / 4,1 / 3,1 / 2)$ & $(2,3,4)$ & $(1,1,1)$ \\
\hline
\end{tabular}

The above comparison matrix table has $\mathrm{CI}=0.0018$. So consistency of our comparison matrix is acceptable. Now consider the pairwise comparison of alternatives according to delivery criterion.

Table 9: Pair Wise Comparisons of Alternatives with Respect to "Delivery" Criterion

\begin{tabular}{|c|l|l|l|}
\hline Alternatives & \multicolumn{1}{|c|}{$V_{1}$} & \multicolumn{1}{|c|}{$V_{2}$} & \multicolumn{1}{|c|}{$V_{3}$} \\
\hline$V_{1}$ & $(1,1,1)$ & $(1 / 8,1 / 7,1 / 6)$ & $(1 / 6,1 / 5,1 / 4)$ \\
\hline$V_{2}$ & $(6,7,8)$ & $(1,1,1)$ & $(1 / 4,1 / 3,1 / 2)$ \\
\hline$V_{3}$ & $(4,5,6)$ & $(2,3,4)$ & $(1,1,1)$ \\
\hline
\end{tabular}

The above comparison matrix table has $\mathrm{CI}=0.1166$. So consistency of our comparison matrix is acceptable. Now consider the pairwise comparison of alternatives according to service criterion.

Table 10: Pair Wise Comparisons of Alternatives with Respect to "Service" criterion

\begin{tabular}{|c|c|c|c|}
\hline Alternatives & $V_{1}$ & $V_{2}$ & $V_{3}$ \\
\hline$V_{1}$ & $(1,1,1)$ & $(1 / 6,1 / 5,1 / 4)$ & $(1 / 8,1 / 7,1 / 6)$ \\
\hline$V_{2}$ & $(4,5,6)$ & $(1,1,1)$ & $(1 / 6,1 / 5,1 / 4)$ \\
\hline$V_{3}$ & $(6,7,8)$ & $(4,5,6)$ & $(1,1,1)$ \\
\hline
\end{tabular}

The above comparison matrix table has $\mathrm{CI}=0.0949$. So consistency of our comparison matrix is acceptable. Now consider the pairwise comparison of alternatives according to performance history criterion.

Table 11: Pair Wise Comparisons of Alternatives with Respect to "Performance History" Criterion

\begin{tabular}{|c|c|c|c|}
\hline Alternatives & $V_{1}$ & $V_{2}$ & $V_{3}$ \\
\hline$V_{1}$ & $(1,1,1)$ & $(1 / 4,1 / 3,1 / 2)$ & $(1 / 6,1 / 5,1 / 4)$ \\
\hline$V_{2}$ & $(2,3,4)$ & $(1,1,1)$ & $(1 / 4,1 / 3,1 / 2)$ \\
\hline$V_{3}$ & $(4,5,6)$ & $(2,3,4)$ & $(1,1,1)$ \\
\hline
\end{tabular}

The above comparison matrix table has $\mathrm{CI}=0.0188$. So consistency of our comparison matrix is acceptable. Similarly normalized non-fuzzy relative weights of each alternative with respect to each criterion has found and given in the table 12 .

Table 12: Normalized Non-fuzzy Relative Weights of Each Alternative with Respect to Each Criterion

\begin{tabular}{|l|c|c|c|}
\hline & $V_{1}$ & $V_{2}$ & $V_{3}$ \\
\hline Quality & 0.645 & 0.133 & 0.222 \\
\hline Price & 0.662 & 0.090 & 0.248 \\
\hline Delivery & 0.075 & 0.328 & 0.597 \\
\hline Service & 0.069 & 0.210 & 0.721 \\
\hline Performance History & 0.107 & 0.263 & 0.630 \\
\hline
\end{tabular}

Weights of the criteria from table No.4 is

Table 13: Weights of Each Criterion

\begin{tabular}{|l|l|}
\hline Criteria & Weights \\
\hline Quality & 0.396 \\
\hline Price & 0.077 \\
\hline Delivery & 0.081 \\
\hline Service & 0.061 \\
\hline Performance History & 0.386 \\
\hline
\end{tabular}

Finally aggregated results for each alternative according to each criterion are calculated. For example score of the first alternative $V_{1}=(0.396 \times 0.645)+(0.077 \times 0.662)+(0.081 \times 0.075)+$ $(0.061 \times 0.069)+(0.386 \times 0.107)=0.358$.

Similarly scores of the alternatives is calculated and given below:

Table 14: Scores of the Alternatives

\begin{tabular}{|l|l|l|l|}
\hline Alternatives & \multicolumn{1}{|c|}{$V_{1}$} & \multicolumn{1}{c|}{$V_{2}$} & \multicolumn{1}{c|}{$V_{3}$} \\
\hline Scores & 0.358 & 0.201 & 0.442 \\
\hline Hierarchy & 2 & 3 & 1 \\
\hline
\end{tabular}

According to the scores, the $3^{\text {rd }}$ alternative has the largest score. So it is considered as the best vendor, with respect to five criteria.

\section{Conclusion}

This paper presents a study using Fuzzy AHP according to five criteria that are very important to the process of vendor selection. It gives scientific framework to rank the alternatives in vendor selection. A discussion has taken to demonstrate the applicability of the proposed frame work. Alternative vendors ranked through literature review, expert option and through AHP with Fuzzy approach. Although there are more models for selecting vendors such as PROMETHEE, TOPSIS, ANP, etc., this proposed frame work gives a new valid and efficient approach for ranking the alternatives. The results of this study can be compared with other MCDM techniques such as PROMETHEE, TOPSIS, ANP, etc., for future research.

\section{References}

[1] Fernandas AC, Sampaio P \& carvalho MS, "Quality Management and supply chain management integration a conceptual model", Proceedings of the International conference on Industrial Engineering \& operations management, Bali, Indonesia (2014).

[2] Szüts A \& Krómer I, "Developing a Fuzzy Analytic Hierarchy Process for Choosing the Energetically Optimal Solution at the Early Design Phase of a Building", Acta Polytechnica Hungarica, Vol.12, No.3, (2015), pp.25-39.

[3] Ishizaka A, "Comparison of Fuzzy logic, AHP, FAHP and Hybrid Fuzzy AHP for new Supplier selection and its performance analysis", International Journal of Integrated Supply Management, Vol.9, No.1/2, (2014), pp.1-22.

[4] Chang DY, "Applications of the extent analysis method on fuzzy AHP”, European Journal of Operational Research, Vol.95, No.3, (1996), pp.649-655.

[5] Kavitha C \& Vijayalakshmi C, "Implementation of supplier evaluation and ranking by improved TOPSIS", Applied Mathematical Sciences, Vol.7, No.46, (2013). 
[6] Kavitha C \& Vijayalakshmi C, "Design and Implementation of Fuzzy Multi Objective Optimization Model for Production Planning", Indian journal of applied research, Vol.3, No.12, (2013).

[7] Manju, K., Sabeenian, R.S., Surendar, A.”A review on optic disc and cup segmentation",(2017) Biomedical and Pharmacology Journal, 10 (1), pp. 373-379.

[8] Coyle JJ, Bardi EJ \& Langley CJ, The Management of Business Logistics: A Supply Chain Perspective. South-Western Thomson Learning, Ohio, (2003).

[9] Tavana M, Azizi F, Azizi F \& Behzadian M, “A fuzzy inference system with application to player selection and team formation in multi-player sports", Sport Management Review, Vol.16, No.1, (2013), pp.97-110.

[10] D’urso MG \& D Masi, "Multi Criteria Decision Making Methods And their applications for human resources", The international Archives of the photogrammetry, Remote sensing and spatial information sciences, (2015).

[11] Ayhan MB, "A Fuzzy AHP Approach for supplier selection problem-A case study in a Gear motor company", International journal of managing value and supply chains, Vol.4, No.3, (2013).

[12] Kilincci O \& Onal SA, "Fuzzy AHP approach for supplier selection in awashing machine company", Experts systems with applications, Vol.38, No.8, (2011), pp.9656-9664.

[13] Singh R \& Sharma SK, "Supplier selection: Fuzzy-AHP Approach", International journal of Engineering Science and Technology, (2011).

[14] Rajnishkumar, "Supplier selection criteria an overview", (2013).

[15] Mwikali R \& Kavale S, "Factors affecting the selection of optimal suppliers in procure management", International journal of Humanities and Social science, Vol.2, No.14, (2012), pp.189-193.

[16] Patil SK and kanth R, "A fuzzy AHP-TOPSIS frame work for ranking the solutions of knowledge Management adoption in supply chain to overcome its barriers", Expert systems with applications, Vol.41, (2014), pp.679-693.

[17] Gold S \& Awasthi A, "Sustainable global supplier selection extended towards sustainability risks from $(1+n)$ th tier suppliers using fuzzy AHP based approach", IFAC-Papers, (2015).

[18] Tang YC \& Lin TW, "Application of the fuzzy analytic hierarchy process to the lead-free equipment selection decision", Int. J. Business and Systems Research, Vol.5, No.1, (2011). 